\title{
Establish In-House: A Pre-Treatment Method of Fat, Oil and Grease (FOG) in Kitchen Wastewater for Safe Disposal
}

\author{
Adel Al-Gheethi ${ }^{1, *}$, Radin Maya Saphira Radin Mohamed ${ }^{\mathbf{1}}$, Welfrad Nyokiew ${ }^{\mathbf{1}}$, \\ Efaq Noman", Amir Hashim Mohd Kassim ${ }^{1}$
}

${ }^{1}$ Micro-Pollutant Research Centre, Faculty of Civil and Environmental Engineering, Universiti Tun Hussein Onn Malaysia, 86400 Johor, MALAYSIA

${ }^{2}$ Department of Applied Microbiology, Faculty of Applied Sciences, Taiz University, Taiz, YEMEN

*Corresponding Author

DOI: https://doi.org/ 10.30880/ijie.2019.11.01.018

Received 20 June 2018; Accepted 05 December 2019; Available online 15 May 2019

\begin{abstract}
The direct disposal of untreated kitchen wastewater generated from the commercial restaurant into the sewerage system lead to increase the sanitary sewer overflow (SSO). In contrast, the disposal into the environment is associated with many adverse effects on the ecosystems. The present study aimed to develop a Fat, Oil and Grease (FOG) trap as a primary treatment of raw kitchen wastewater based on the gravity separation principle. The optimization of the separation process was determined using response surface methodology (RSM) based on flow rate and peak time of kitchen wastewater. The results revealed that the optimization removal of FOG was $93.48 \%$ with $8.27 \mathrm{~L} / \mathrm{min}$ of flow rate and on 10.27 am of time sampling. FOG concentrations have dropped from 766.67 $\mathrm{mg} / \mathrm{L}$ to $50 \mathrm{mg} / \mathrm{L}$. These findings indicated that the FOG Trap was a reliable and exhibited efficiency for FOG removal from the kitchen wastewater.
\end{abstract}

Keywords: Trap, FOG, Optimization, RSM, SEM

\section{Introduction}

The huge amounts of fat, oil and grease (FOG) discharged into the sewerage systems is associated with the sewer blockage [sanitary sewer overflows (SSOs)] as a result of the solidification of FOG. SSOs is correlated with the occurrence of pathogens, nutrients, and solids pollutions of the natural water system which receiving these wastes [1]. In USA, at least 10350-36000 SSOs cases are recorded annually. In contrast, there are no information on the situation in Malaysia, however, the increasing of the total population of Malaysia with $1.5 \%$ of population growth rate is correlate with huge quantities of the generated wastewater from different sectors [2]. It has stated that the total quantity of wastewater generated from municipal and industrial sectors is 2.97 billion cubic meters [3].

The heavy load of FOG concentrations in the wastewater treatment system reduce the efficiency of the treatment process. Therefore, the kitchen wastewater should be subjected for a pre-treatment process for reducing of FOG before the discharge into the sewerage system [4]. The trap is one of the effective pre-treatment methods to separate and remove the FOG in the kitchen wastewater [5], [6]. Currently, different types of FOG traps are available in the Malaysia market such as FOGHog Manufactured by BioMicrobics as presented in previous work [7]. However, the current FOGs have several disadvantages such as high cost of the installation and operation as well as the maintenance. Hence, most of the restaurants have not applied theses system for removing the FOGs from the wastewater before the final disposal into the environment. Nonetheless, the restaurants depend only on using screening process for separating the large debris such as 
bone, food waste and kitchenware and discharge the liquid wastes in to the surrounding environment causing a bad odour around the restaurant [4].

The current work aimed to develop a FOG trap for restaurant and domestic residential applications. The efficiency of FOG trap was compared to the Malaysia Environment Act (1974) effluent legislation standard A and B which indicated that the treated wastewater should has less than $5 \mathrm{mg} / \mathrm{L}$ for Standards A and less than $10 \mathrm{mg} / \mathrm{L}$ of FOG concentrations for Standards B. In the current work, the establishment of a FOG trap create opportunities to the potential manufacturer to expand their market in Malaysia and to international market due to the simplicity and the effectiveness of FOG pretreatment process.

\section{Materials and Methods}

\subsection{FOG Trap Establishment}

The methodology used in this work is illustrated in Fig. 1. FOG trap was made of transparent Acrylic Sheets with 20.6 L of capacity as detailed in Table 1. The schematic FOG trap design detail drawing is presented in Fig. 2. The transparent FOG allowed the user to monitor the operational of the kitchen wastewater and remove the sludge accumulate at the bottom of FOG trap and the coarse filter screen. The installation of FOG trap is shown in Fig. 2. The FOG trap was installed at a level surface to ensure the FOG trap operate efficiently.

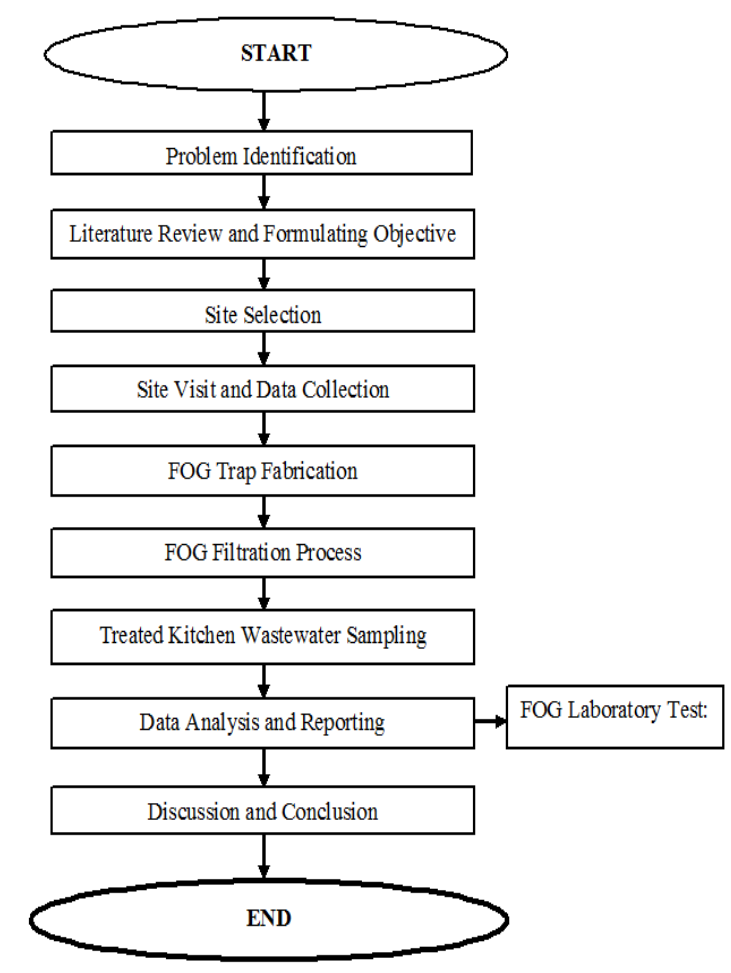

Fig. 1 - Research flow chart

Table 1 - Volume capacity detail of the FOG treatment system

\begin{tabular}{ccc}
\hline Notation & Compartment & $\begin{array}{c}\text { Volume } \\
(\mathbf{L})\end{array}$ \\
\hline $\mathrm{A}$ & Screening & 2.5 \\
$\mathrm{~B}$ & $\begin{array}{c}\text { Primary } \\
\text { Sedimentation } \\
\text { Secondary }\end{array}$ & 11.7 \\
$\mathrm{C}$ & $\begin{array}{c}\text { Sedimentation Tank } \\
\text { FOG Separation } \\
\text { Chamber }\end{array}$ & 3.1 \\
$\mathrm{D}$ & FOG Trap Capacity & 1.5 \\
$\mathrm{E}$ & & \\
\hline
\end{tabular}




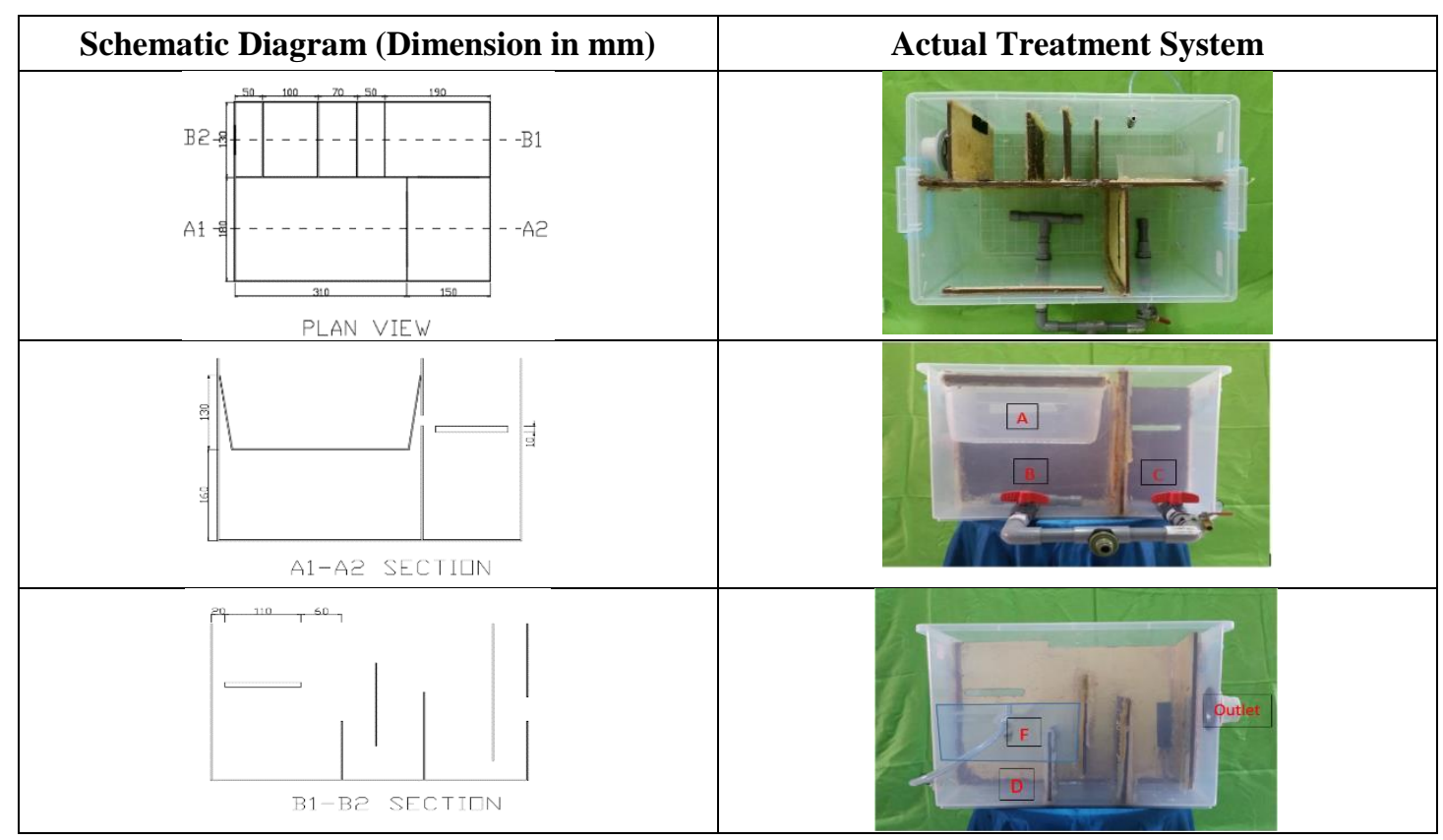

Fig. 2 - Schematic FOG trap design detail drawing

\subsection{FOG Trap Design Optimization}

The best removal of FOG was optimized using response surface methodology (RSM) based on two independent variables, including flowrate (A) (8 to $12 \mathrm{~L} / \mathrm{min})$ and sampling time $(B)(8.00$ am to $2.00 \mathrm{pm})$. The central composite design (CCD, expert 6.0.10) method was used to determine the number of experiments (9 runs) to be evaluated for the optimization of the variables and responses. The results were analysed for first order response surface equations of the model. The significance of the variables on the removal process was analysed using the analysis of variance (ANOVA, $p<0.05)$. The adjusted coefficient of determination $\left(R^{2} a d j\right)$ was used for checking the fit of the linear model. The interactions between the factors and their effects on the removal of FOG were presented using a three-dimensional graphical representation of the system behavior, called RSM.

\subsection{Kitchen Wastewater Sampling}

The sampling was conducted between 8.00 am and $2.00 \mathrm{pm}$ which represent the high activities of cooking and dishwashing in the restaurants. The samples were collected in $150 \mathrm{~mL}$ plastic bottle and transfected to the laboratory for the chemical analysis of FOG as described by APHA [8], while large amounts of the samples (25 L) were collected for filtration process using FOG trap.

\subsection{FOG Filtration Process}

The filtration process of removing FOG was conducted in an enclosed FOG trap chamber. The influents were flow into the FOG trap chamber and the initial screening was performed to remove the medium size of kitchen waste such as leftover food wastes. The fine debris was sink at the retention chamber while the floatable material float at the water surface. The baffle acted as flow equalizer to prevent turbulence in the treatment system. The total retention time of FOG trap was varies to determine the optimum retention time of pre-treatment process.

The floatable FOG float at the water surface and being removed through the FOG extraction piping to the FOG collection container. The daily desludging work was carried out to remove the accumulated sludge at the bottom FOG trap trough the desludging outlet at the bottom of the FOG trap chamber. The treated kitchen wastewater effluents were filtrated through hair filter as absorbent media and then discharged into the drainage or sewer line by gravity flow. The flow rate of the influent was manipulate in the range of 7.17 to $12.83 \mathrm{~L} / \mathrm{min}$ as refer to the flow rate of the tap water in Malaysia which is relate to the flow of the kitchen wastewater in the FOG trap treatment system in real situation. The concentrations of FOG in the treated effluents collected form the outlet was determined according to APHA [8], while the surface properties of hair adsorbent was observed by Scanning Electron Microscope (SEM).

The FOG trap removal efficiency of FOG was calculated by the Eq. (1).

$$
\text { Efficiency }(\%)=\frac{\mathrm{A}-\mathrm{B}}{\mathrm{A}} \times 100 \%
$$

where $\mathrm{A}=$ untreated wastewater value and $\mathrm{B}=$ treated wastewater value. 


\section{Results and Discussion}

\subsection{Treatment System Description}

The FOG trap treatment unit consisted of three compartments included primary and secondary sedimentation and FOG trap compartment, in which the influent from the kitchen sink discharge was flow through $3 \times 3 \mathrm{~mm}$ screen mesh. The influent of trap flow rate was $12.83 \mathrm{~L} / \mathrm{min}$ as the water tap was fully open during dish washing. The primary sedimentation compartment was combined with the screen chamber. The screen filter the coarse waste such as vegetable and the rice with dimension above $3 \mathrm{~mm}$. The primary sedimentation and secondary compartment kept the heavy waste settle at the bottom for desludging work on the trap system using the de-sludge valve located at the bottom of the sedimentation tank. The FOG chamber acted by separating of FOG as a function of gravity. The less density of oil float at the top surface of the water at the FOG chamber which drain using the valve to remove all the FOG trap in the chamber. The FOG absorber media is placed at the end of the system to absorb any trace of FOG that passes through the FOG chamber. The FOG absorber media consist of human hair which has the good characteristic of absorbing small traces of oil before discharge into the sewer.

\subsection{FOG Removal Efficiency}

The FOG removal efficiency as a function of flow rate and sampling time is illustrated in Table 2. The results revealed that the highest FOG removal (94.81\%) was recorded with $8 \mathrm{~L} / \mathrm{min}$ of flow rate and at 9 am of sampling time.

Table 2 - Fat, Oil and Grease (FOG) Trap removal Efficiency for Kitchen Wastewater

\begin{tabular}{ccccc}
\hline Run & Sampling Time & Flow rate L/min & $\begin{array}{c}\text { FOG } \\
\text { Removal (\%) }\end{array}$ & Predicted Removal (\%) \\
\hline 1 & $8.17 \mathrm{am}$ & 10.00 & 90.909 & 88.861 \\
2 & $9.00 \mathrm{am}$ & 8.00 & 93.333 & 94.808 \\
3 & $9.00 \mathrm{am}$ & 12.00 & 70.000 & 72.603 \\
4 & $11.00 \mathrm{am}$ & 7.17 & 94.118 & 92.898 \\
5 & $11.00 \mathrm{am}$ & 10.00 & 90.196 & 90.196 \\
6 & $11.00 \mathrm{am}$ & 12.83 & 66.667 & 63.852 \\
7 & $1 . .00 \mathrm{pm}$ & 8.00 & 91.111 & 92.543 \\
8 & $1.00 \mathrm{pm}$ & 12.00 & 71.111 & 73.670 \\
9 & $2.13 \mathrm{pm}$ & 10.00 & 90.000 & 88.013 \\
\hline
\end{tabular}

The results revealed that the flow rate and sampling time factors contributed mainly in the removal of FOG. Moreover, the optimum operation for the removal efficiency percentage was varied with each factor separately and as combined factors. The collected data were analysed using the analysis of variance (ANOVA, $\mathrm{p}<0.05$ ). The independent factors which included flow rate values $(8 \mathrm{~L} / \mathrm{min}-12 \mathrm{~L} / \mathrm{min})$ and sampling time $(8.00 \mathrm{am}-2.00 \mathrm{pm})$, were selected in order to examine the comprehensive factors which might have effects on the reduction of FOG concentration in the water sample. The regression coefficients for reducing FOG in the kitchen wastewater at the end of the treatment process are presented in Table 3. The effect of flow rate factor was considered strong significant at P-value $<0.01$ and $99 \%$ of the confidence level and the sampling time P-value is $>0.05$ and indicate the sampling time has no significant effect on the removal the FOG in the wastewater.

The synergistic effects of the examined factors were investigated in the current work based on ANOVA analysis. In the case of FOG removal, the results of the analysis revealed that flow rate factor has a negative significant synergic effect on FOG removal efficiency $(\mathrm{P}<0.05)$, which does mean that the increasing of flow rate associated with low removal of FOGs. The significant level of the flow rate (A) and sampling time (B) toward effecting the FOG removal efficiency can be categories as non-significant, $(\mathrm{P}>0.05)$.

The summary of the analysis of variance (ANOVA) for the quadratic model noted that the regression model for the removal of FOG was significant at a confidence level of $95 \%(p<0.05)$ with determination coefficients $\left(R^{2}\right.$ adj) equal to 0.95 for FOG, indicating the aptness of the model.

The second-order model describes the significant relationship between the removal of FOG and selected factors in terms of coded factors as given by Eq. (2).

$$
Y_{F O F}=90.2-10.27 A-0.3 B-5.91 A^{2}-0.88 B^{2}+0.83 A B
$$

The Eq. (2) is generated by the regression coefficient to predict the FOG removal efficiency at the different point of the parameter on the flow rate and time relationship. 
Interactions between the variable factors with the investigated range at the actual factor of the centre point were performed using the response surface methodology (RSM) analysis. Fig. 2 shows the 3-dimensional relationship of flow rate and the sampling time on the FOG removal percentage using the expert design software. The figure shows that the time is not significant effect on the FOG removal. Meanwhile, the change of flow rate does contribute significant effect on the FOG treatment system in treating the FOG concentration in the kitchen wastewater.

Table 3 - Analysis of the Variance (ANOVA) Of the Response Surface Quadratic Model for the Removal of FOG from Kitchen Wastewater by Using the Trap Treatment System

\begin{tabular}{cccccc}
\hline Source & Sum of Squares & DF & Mean Square & F Value & $\begin{array}{c}\text { p-value } \\
\text { Prob }>\text { F }\end{array}$ \\
\hline Model & 1090.26 & 5 & 218.0529 & 43.4785 & $<0.0001$ \\
A & 843.671 & 1 & 843.6718 & 168.2233 & $<0.0001$ \\
B & 0.71791 & 1 & 0.7179 & 0.1431 & 0.7164 \\
A2 & 243.014 & 1 & 243.0141 & 48.4556 & 0.0002 \\
B2 & 5.38024 & 1 & 5.3802 & 1.0728 & 0.3348 \\
AB & 2.77722 & 1 & 2.7772 & 0.5538 & 0.4810 \\
Residual & 35.1063 & 7 & 5.0152 & & \\
Lack of Fit & 35.1063 & 3 & 11.7021 & & \\
Pure Error & 0 & 4 & 0 & & \\
Corr Total & 1125.37 & 12 & & & \\
\hline
\end{tabular}

The use of a single parameter in terms of other fixed parameters may not be suitable to optimize operational conditions. The ability to reduce experimental trials that are required to express multiple trials and interactions makes RSM a better optimization technique. The optimizing of the natural composite in reducing FOG was conducted using the point optimization technique by the Design Expert software. The conditions for the best operation of adsorption process were performed based on the results obtained from the screening of independent factors which revealed the possible direction for maximizing the removal process of the FOG contaminant. However, the results revealed that the sampling time was not a significant factor, therefore others factors should be investigated to optimize the operating process of FOG trap. Moreover, the results indicated that the FOG trap has an efficiency to remove a wide range of FOG load from wastewater.

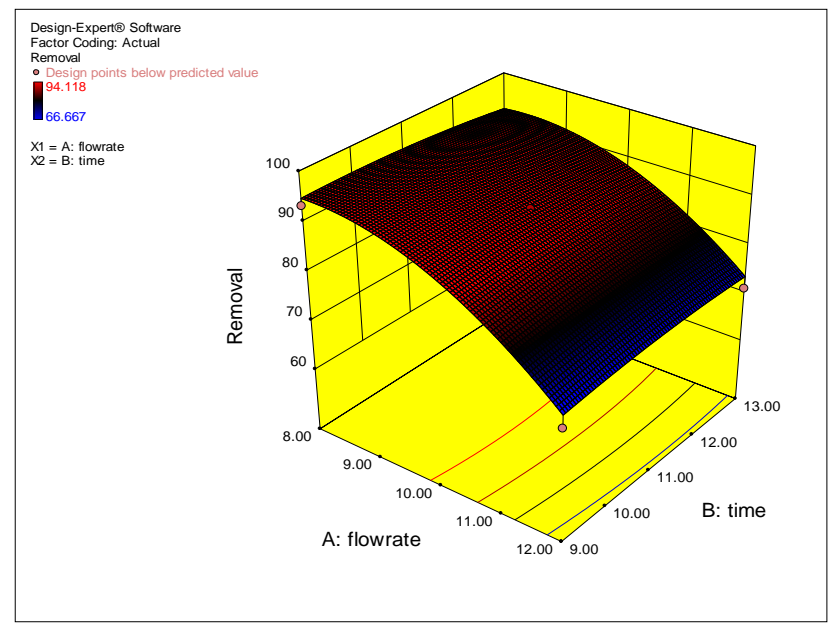

Fig. 3 - Three-dimensional relationship of flow rate and the sampling time on the FOG removal percentage

The optimal operation parameters of the treatment process for the removal efficiency of FOG was recorded at flow rate $8.27 \mathrm{~L} / \mathrm{min}$ at 10:27 am. The FOG removal was 93.48 vs. $94.84 \%$. A laboratory experiment was carried out on the suggested parameter variable to confirm the actual efficiency of FOG removal in the treatment system according to Table 4. 
Table 4 - Best operating parameters of trap for FOG removal

\begin{tabular}{cccc}
\hline Flow rate & Time & $\begin{array}{c}\text { Actual FOG } \\
\text { Removal (\%) }\end{array}$ & $\begin{array}{c}\text { Predicated FOG } \\
\text { Removal (\%) }\end{array}$ \\
\hline $\begin{array}{c}8.27 \\
\text { L/min }\end{array}$ & $\begin{array}{c}10.27 \\
\text { am }\end{array}$ & 93.48 & 94.84 \\
\hline
\end{tabular}

\subsection{Scanning Electron Microscope (SEM) of Hair Adsorbent}

SEM test for the hair surface texture which was used as a filtration and adsorbent of the FOGs remaining in the treated wastewater and to improve the quality of the wastewater for safe disposal. SEM analysis was performed to observe the hair surface texture as FOG absorbent media using SEM before and after undergoing FOG treatment process. The electrons interact with atoms in the sample, producing various signals that contain information about the sample's surface topography and composition. SEM is widely used to identify phases based on qualitative chemical analysis and crystalline structure. It cans measure of very small features and objects up to $50 \mathrm{~nm}$ in size. As the SEM image shown in Fig. 3, the comparative between the before and after go through the FOG treatment process is that the rough surface of the hair look much smoother. The FOG is actually not completely absorb into the hair, instead the oil coat the hair latching onto crack and hole. The FOG contaminant in the kitchen waste water will be absorb in the treatment process.

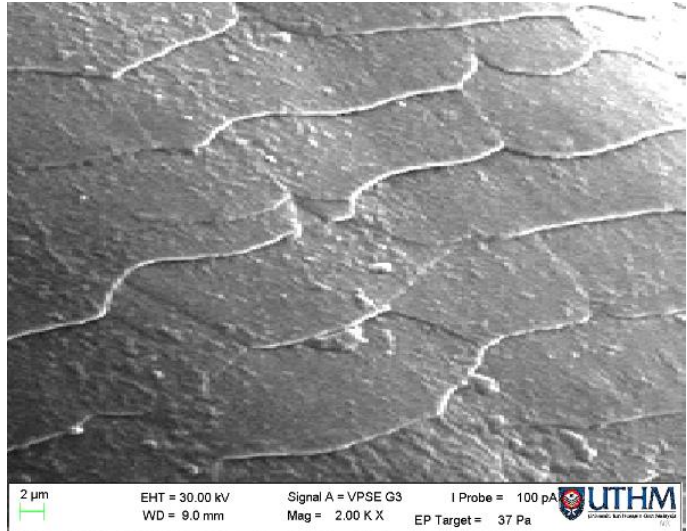

(a) Before treatment

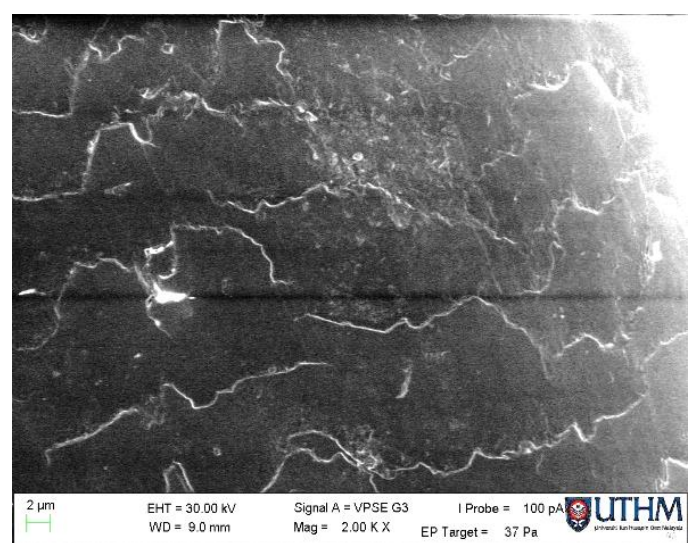

(b) After treatment

Fig. 4 - SEM Image of hair surface texture with 2000 times magnification

\section{Conclusions}

It can be concluded that the grease trap was effective in reducing the concentration of the FOG in the kitchen waste water. Based on the result gather from the laboratory experiment, the highest FOG removal percentage is $93.48 \%$ at the optimization run of the treatment system. Even though the trap treatment system is efficient in removing the FOG concentration out of the wastewater, the effluent of water discharge still did not meet the Malaysia Environment Act (1974) effluent legislation standard A and standard B with less than $5 \mathrm{mg} / \mathrm{L}$ must be less than $10 \mathrm{mg} / \mathrm{L}$ of FOG concentrations. Therefore, a development in the current FOG trap is need to improve the quality of the wastewater to meet the standards.

\section{Acknowledgement}

Special gratitude goes to the laboratory technicians at the Micro-pollutant Research Centre, Faculty of Civil and Environmental Engineering, Universiti Tun Hussein Onn Malaysia (UTHM) for providing the facilities for this research. The authors also wish to thank the Research Management Centre (RMC) UTHM for providing Tier 1 grant H207 for supporting this research.

\section{References}

[1] United State Environmental Protection Agency (2004). Report to congress on impacts and cotrol CSOs and SSOs. Washington: United State Environmental Protection Agency.

[2] Department of Statistics Malaysia (2015). Labour force survey. Press Release. Putrajaya: Department of Statistics Malaysia, pp. 5-9. 
[3] Mat, E. A., Shaari, J., and How, V. K. (2012). Wastewater production, treatment and use in Malaysia, A report., Putrajaya: Ministry of Health, Engineering Services Division, pp. 1-13.

[4] Chen, X., Chen, G., and Yue, P. L. (2000). Separation of pollutants from restaurant wastewater by electrocoagulation. Separation and Purification Technology, 19(1), 65-76.

[5] Rahmat, S. N., Algheethi, A., Mohd Ali, A. Z., Mohammad Razi, M. A., and Adnan, M. S. (2018). Field performance of a constructed litter trap with oil and grease filter using low-cost materials. International Journal of Integrated Engineering, 10(2), 128-131.

[6] Rahmat, S. N., Mohd Ali, A. Z., Wan Ibrahim, M. H., and Alias, N. A. (2016). Oil and grease (O\&G) removal from commercial kitchen waste water using carbonised grass as a key media. MATEC Web of Conferences, 87, 01010.

[7] Mohamed, R. M. S., Al-Gheethi, A., Welfrad, A. N., and Amir Hashim, M. K. (2018). Development in-house: A trap method for pretreatment of fat, oil, and grease in kitchen wastewater. In: Handbook of Environmental Materials Management, pp. 1-16.

[8] American Public Health Association (2012). Standard methods for the examination of water and wastewater (22nd ed.). In Rice, E. W., Baird, R. B., Eaton A. D., and Clesceri, L. S. (eds.). Washington: American Public Health Association. 